Çukurova Üniversitesi Mühendislik Mimarlık Fakültesi Dergisi, 33(2), ss. 113-124, Haziran 2018

Çukurova University Journal of the Faculty of Engineering and Architecture, 33(2), pp. 113-124, June 2018

\title{
Bir Deponi Alanı Sızıntı Sularının Çevresel Etkilerinin Jeofizik ve Su Kimyası Yöntemleriyle İncelenmesi
}

\author{
Sevda ÖZEL*1 \\ ${ }^{1}$ Cumhuriyet Üniversitesi, Mühendislik Fakültesi, Jeofizik Mühendisliği Bölümü, Sivas
}

$\ddot{\mathbf{O} z}$

Geliş tarihi: 23.08.2017_ Kabul tarihi: 29.06.2018

Yapılan çalışmada Sivas deponi alanından çıkan sızıntı sularının yarattığı kirliliğin yayılımı jeofizik ve su kimyası yöntemleri ile incelenmiştir. Sızıntı suyunun akış yönü bölgede egemen olan jeolojik süreksizlikler ve jeomorfolojik yapılar tarafından denetlenmektedir. Buna göre, yüzeydeki sızıntı suyu Haçin deresinden, yakınındaki Kızılırmak nehrine doğru akmaktadır. Bu çerçevede, Haçin deresinin iki tarafında yayılan sızıntı suyu kirliliğinin zemindeki yayılımı irdelenmiştir. Kirliliğin varlığı ve yayılımı, elektromanyetik iletkenlik (EMC-Electromagnetic Conductivity) yöntemi ve alınan su örneklerinin su kimyası analizleri ile belirlenmişsir. EMC ölçümlerinden elde edilen görünür iletkenlik grafikleri, sızıntı suyunun yataydaki yayılım sınırlarını göstermiştir. Su kimyası analizleri ise sudaki kirliliğin sızıntı suyundan kaynaklandığını göstermiş̧ir. Sonuç olarak yöredeki Kuvaterner yaştaki toprak örtünün yanı sıra yüzey ve yeraltı su kaynaklarının sızıntı suyundan ileri gelen kirliliğin tehdidi altında olduğu belirlenmiştir. Oluşan kirliliğin ise katı atık deponi alanının daha uzun süre kullanılacağı gözetilerek, acilen ÇED (Çevresel Etki Değerlendirme) süreci çerçevesinde denetim altına alınması gerektiği ortaya konulmuştur.

Anahtar Kelimeler: Jeofizik-görünür elektromanyetik iletkenlik (EMC), Su kimyası, Deponi alanı, Sizıntı suyu-kirlilik, Sivas

\section{Studying of Environmental Effects of a Disposal Area Leachates with Geophysical and the Water Analyses Methods}

\begin{abstract}
In the study, the pollution spread out by the leachates coming from the disposal area (Sivas) has been studied with geophysical and the water analyses methods. The flow direction of the leachates is controlled by geological discontinuities and geomorphological structures, dominant in the region. Accordingly, the leachate in the surface flow from the Haçin creek to nearby Kizılırmak river. In this framework, the leachate pollution spreading in the underground of both sides of the Haçin creek has been studied. The leachate spreading in the underground has been evaluated by using the methods of Electromagnetic Conductivity (EMC) and the water analyses of samples obtained from the soil. Apparent conductivity graphics have been obtained from EMC measurements. The water analyses data show that the pollution in the leachate has been originated from the leachate. As a result, it has been identified that the underground and surface water resources, as well as Quaternary soil cover in the region are under the risk of the leachate pollution. Considering the solid waste landfill area to be used for a long period of time, it has been demonstrated that the pollution should be taken urgently under control within the framework of the EIA (Environmental Impact Assesment) process.
\end{abstract}

Keywords: Geophysics-apparent electromagnetic conductivity (EMC), Water chemistry, Disposal area, Leachate-pollution, Sivas

*Sorumlu yazar (Corresponding author): Sevda ÖZEL, sozel@cumhuriyet.edu.tr 


\section{GíRiş}

Deponi alanlarından yayılan sızıntı suları toprağa, yüzey ve yeraltı sularına karışarak uzun mesafeler boyunca taşınabilirler. Çeşitli toksik kimyasalları da içeren bu sular, yüzey veya yeraltı sularına karıştığında çok geniş alanları kirletirler. $\mathrm{Bu}$ nedenle günümüzde önemli bir çevre sorunudur. $\mathrm{Bu}$ sorunları belirlemede, çevre jeofiziği çalışmalarının önemli bir yeri vardır [1]. Sızıntı suyunun yeraltındaki yayılımı başlıca elektrik ve elektromanyetik yöntemler olmak üzere jeofizik yöntemlerle de incelenmektedir. Özellikle sı̆̆ alanlarda doğru akım özdirenç (DCR-Duration Current Resistivity) yöntemi ve elektromanyetik iletkenlik (EMC-Electromagnetic Conductivity) yöntemi kirlilik yayılımını belirlemede sıklıkla kullanılır [2-6]. Deponi alanlarından çıkan sızıntı sularını izleme sistemleri de geliştirilmiştir [7-9]. Sıvı inorganik atıkların dağılımını DCR ve EMC yöntemleri ile incelenmiştir [10]. Çevresel uygulamalarda çok yararlı olan bu çalışmaların çoğunda araştırmacılar, DCR ve EMC yöntemleri birlikte kullanmışlar ve yüzeye yakın alanların ve yeraltının kirlilik yayılımını çoğunlukla 2B (İkiBoyutlu) ve 3B (Üç-Boyutlu) olarak incelenmişlerdir [1-6].

$\mathrm{Bu}$ çalışmada ise yaklaşık 16 yıldır kullanılmakta olan Sivas ili düzensiz katı atık deponi alanından yayılan sızıntı sularındaki organik-inorganik kirleticilerin varlığı, deponi alanı ve Kızılırmak nehri arasındaki alanda ve kısmen Kizılırmak nehrinde, jeofizik ve su kimyası yöntemleriyle incelenmiştir (Şekil 1, Şekil 2). Deponi alanının güneyindeki Haçin deresi ile Kızılırmak nehrine taşınan sızıntı sularının, düzenli depolamaya geçmek için 2009 yılında havuz inşaatlarına başlamasıyla, yeni ilk deşarj yeri değişmiştir (Şekil 1). Bu sular, 2009 y1lı ortasından sonra, bir bölümü tesisin inşaat bölgesinden (geri kazanım, kompostlama ve atıksu arıtma amaçlı havuzlar ile yol ve işletme binası yapımının devam ettiği bölüm) geçen borularla ve bir bölümü de düzensiz bir şekilde inşaat bölgesindeki havuzların kenarları boyunca akarak, yeni ilk deşarj yerinde birleşip Haçin deresine karışarak, Kızılırmak'a ulaşmaktadır (Şekil 1). Ayrıca deponi alanı sızıntı suları hala arıtılmadan uzaklaştırılmaktadır [1].

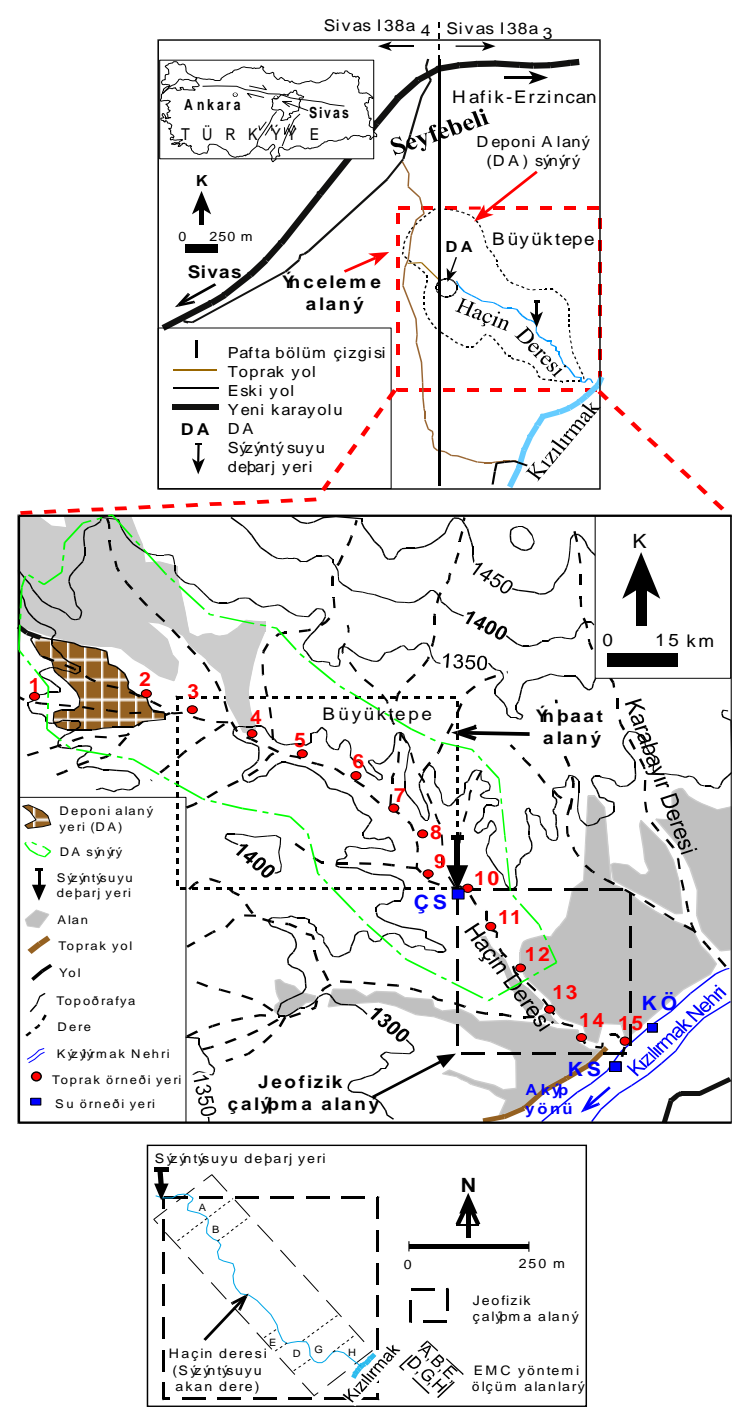

Şekil 1. İnceleme alanı, topoğrafya ve jeofizik çalışma haritaları Özel, (2010) ve Özel vd. (2017)'den düzenlendi

İnceleme alanının temelini oluşturan Kuvaterner yaşlı ve geçirimli alüvyonal birimli kayatürlerinin büyük bir bölümü akifer ya da en azından sınırlı bir akifer niteliğinde olup, yeraltısuyu seviyesi yüksek olduğu dönemlerde, kimi yerlerde $4 \mathrm{~m}$ ve atık alanının güneyinde, Kızılırmak dolayında 2-3 m kadar yüzeye yakındır. Yapılan sondajlarda da, yeraltı su seviyesi yüzeye yakındır [11]. Bu yakınlıktan dolayı, toprak, yüzey ve yeraltı suları kirlenme riski ile karşı karşıyadır. Özellikle yağışı 
dönemlerde yağış sularının, yüzey ve yüzeyaltı akışı biçiminde ya da geçirimli birimden yeraltısuyuna kadar kirleticileri taşınması mümkündür. Yeraltısuyu seviyesinin kirlenmiş olan zona birkaç metre yakın mesafede olması, yağışla birlikte yeraltı su tablası da yükseleceğinden, bu kirleticiler, daha uzak ve daha derin zonlara taşınarak yeraltı ve yüzey sularını kirletebilirler [1]. Bu durumda çöp kaynaklı kirleticiler, bitkileri ve canlı yaşamını daha geniş bir alanda tehdit edecektir. Bu kirliliğin çevre üzerindeki etkileri gözden geçirildiğinde, [1]'e göre dereye yakın yerlerde tarımsal amaçlı ekilen bitkilerin (ayçiçeği, buğday ve mercimek) yeterince gelişmediği ve bitkiler üzerinde yoğun olarak koyu lekeler oluştuğu saptanmıştır. Buna rağmen, bölgede halen tarım yapılmaktadır ve yapılan tarımın ürün kalitesi, çeşitliliği ve verimi de düşük olmaktadır.

Toprak ve su kirliği ile zemin sorunlarını irdelemek amacıyla bölgede çevre jeolojisi, çevre jeotekniği ve çevre jeofiziği çalışmaları yapılmıştır $[1,6,12,13]$. Oluşan kirliliğin yeraltındaki yayılımı konusundaki ilk jeofizik çalışmalar ise Özel [1] tarafından çevre jeofiziğinde önemli yeri olan DCR ve EMC yöntemleri ile incelenerek, kirliliğin boyutları 2B-3B özdirenç kesitleriyle ve iletkenlik haritaları ile ortaya konulmuştur [6]. Makale konusu çalışmada ise kirlilik, su analizleri sonuçları ve 1B (Bir-Boyutlu) olarak EMC grafikleri ile irdelenmiştir. Ayrıca sunulan bu çalışma, düzenli deponi alanına dönüştürülecek olan sahanın işletme sürecinde daha da artması olası kirliliğin, zamanında denetlenmesi açısından da gereklidir.

\section{MATERYAL VE YÖNTEMLER}

\section{1. İnceleme Alanının Çevre Jeolojisi}

Deponi alanı ve yakın çevresinde yüzeylenen egemen jeolojik birimler, Selimiye formasyonu (Ts), Hafik Formasyonu (Th) ve Kuvaterner (Qa) yaşlı oluşuklarla temsil edilmektedir (Şekil 2). Selimiye Formasyonu, deponi alanında yüzeylenen en alt düzey olup, ağırlıklı olarak OligosenMiyosen yaşlı karasal kırıntılı kayalardan oluşur
[14-15]. Genel olarak morumsu, kırmızı yer yer alacalı gri renkte olan çakıltaşı, kumtaşı, silttaşı ve çamurtaşı ardalanması ile temsil edilen (Ts, SWML) bu birim çeşitli düzeylere ayırtlanmıştır [11-12]. Kaya türleri bol oranda kırıklı ve eklemli olup, gözenekli ve geçirgen bir yapıyı yansıtmakta ve deponi alanı ağılıklı olarak e ve f düzeyleri üzerinde yer almaktadır.

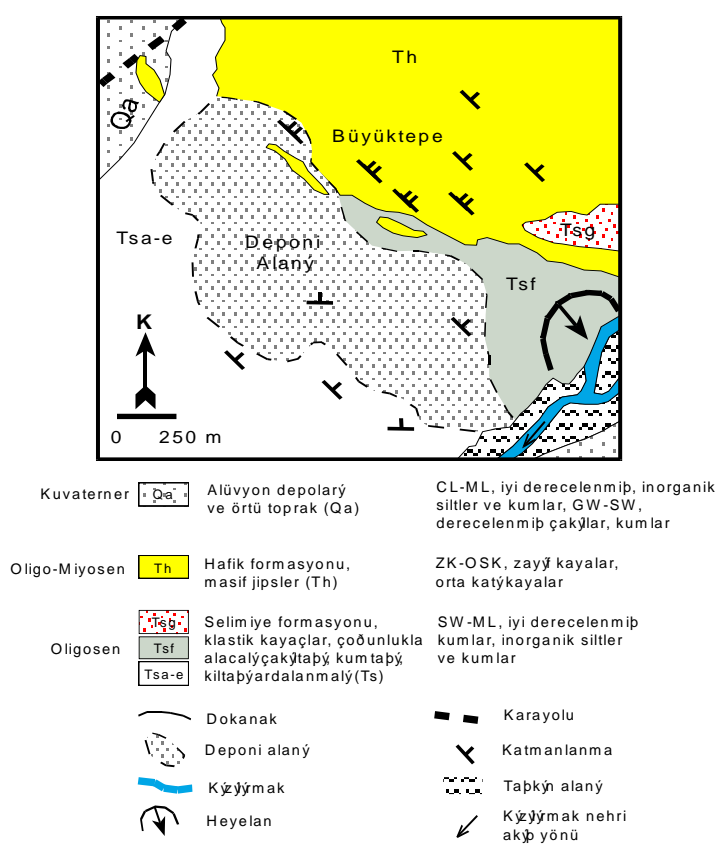

Şekil 2. İnceleme alanı jeoloji haritası (Özel ve ark. [6])

Sivas havzasında oldukça geniş yayılım sunan ve ağırlıklı olarak masif jipslerden oluşan Hafik Formasyonu (Th) ise Oligo-Miyosen yaşlı bir birimdir [14]. Başlıca masif jips ve jips ara katkılı kırıntılı kayalardan oluşan (Th, ZK-OSK) bu birim, atmosferik süreçlerin etkisiyle kolaylıkla çözünebilen bir yapıdadır ve bileşiminde evaporit grubu minerallerden jipsin $\left(\mathrm{CaSO}_{4} 2 \mathrm{H}_{2} \mathrm{O}\right)$ yanı sira anhidrit $\left(\mathrm{CaSO}_{4}\right)$ ve kayatuzu $(\mathrm{NaCI})$ da bulunur. $\mathrm{Bu}$ evaporit grubu mineraller, su ile temas ettiklerinde kolaylıkla çözünürler. Su, ortamı terk ettiğinde ise bu mineraller tekrar kristalleşebilir, iyonlar yer değiştirerek yeni mineraller oluşabilir ya da mineraller birbirine dönüşebilirler. $\mathrm{Bu}$ minerallerin oluşturduğu kayatürlerinin egemen olduğu havzalarda su kalitesi kolaylıkla 
bozulmaktadir ve evaporit grubu minerallerin çözündüğü yüzey ve yeraltı suları doğal olarak kirlenmektedir [12-13]. Kuvaterner yaşlı alüvyonlar ve toprak örtü ise akarsu vadilerinde ve kimi düzlüklerde daha kalın bir düzey halinde görülmektedir (Qa, CL-ML-GW-SW). Alüvyonlar, genel olarak tutturulmamış ya da gevşek tutturulmuş ve taşınma evresi geçirmiş çakıl, kum ve çamur boyutundaki kırıntılı kaya türleriyle temsil edilmektedir. Toprak örtü ise ince taneli ve yerliyerinde oluşmuş, daha çok ince taneli bir kaya türü topluluğudur. Ayrıca traverten ve yamaç molozu ya da alüvyon konileri deponi alanı dolayında yer yer izlenir.

Kuvaterner yaşlı alüvyon ve Oligosen-Miyosen yaşlı Selimiye formasyonu üzerinde yerli yerinde oluşmuş toprak, deponi alanının zemini durumundadır. Çeşitli yapısal unsurların da izlendiği deponi alanı, KB-GD gidişli ve katmanların dikleştiği bir antiklinalin kuzeybatı kanadı üzerinde olup, Oligosen yaşlı kırıntılı birimlerin katmanlanması yaklaşık KB-GD gidişlidir. $\mathrm{Bu}$ kıvrımın ana ekseninde katmanların eğimi 10-15 derece, kanatlara doğru 35-45 derece dolayındadır. $\mathrm{Bu}$ yap1 sızıntı sularının KB-GD gidişli Haçin Deresi boyunca akışını denetlemektedir [13-15]. Sonuç olarak yukarıda sunulan çevre jeolojisine dair bilgiler, deponi alanından kaynaklanan sızıntı sularının önlemler alınmazsa çevreyi kirletebileceği, ancak, kirliliğin boyutlarına dair mevcut durumu ortaya koymak üzere toprak kimyasının yanı sıra su kimyası ve jeofiziksel yöntemlere de ihtiyaç olduğunu açıkça göstermektedir.

\subsection{Su Kimyası Çalışmaları}

Her türlü atığın denetimsiz bir şekilde bırakıldığı düzensiz katı atık deponi (çöp) alanlarında, atıkların depolanması sırasında ortaya çıkan sızıntı sularının çevreyi kirletmesi, yeraltı ve yüzey sularını, toprak kalitesini, bitki, hayvan ve insan yaşamını tehdit etmektedir. Özel [1], inceleme alanından toprak örnekleri alarak toprağın ağır metal analizlerini yapmış ve çöp kaynaklı kirliliğe sebep olan ağır metalleri ve bu ağır metallerin Kızılırmak'a taşındığını belirlemiştir [1-6]. Bu makalede ise çevresel etkiler su analizi çalışmaları ile de gösterilmiştir. $\mathrm{Bu}$ amaçla 1 adet atıksu örneği yeri ve 2 adet yüzeysuyu örneği alma yeri belirlenmiștir. Bu yerler, ÇS (Çöp Sızıntı suyu), KS (Kızılırmak sonrası suyu) ve KÖ (Kızılırmak öncesi suyu) olarak adlandırılmıştır (Şekil 1). Alınan su örneklerinde, arazi ortamında ve laboratuarda su analizleri yapılmıştır (Çizelge 1 ve Çizelge 2, Şekil 3 ve Şekil 4). Bu analizlerde çöp sızıntı ve yüzey sularının su kimyası özelliklerinin zamanla değişimi bir yil (12 ay) boyunca izlenmiştir. Her ay düzenli olarak sızıntı suyu ilk deşarj yerinden (Şekil 1'de; ÇS, Örnek-10 noktasından), sızıntı sularından ileri gelen kirliliği tanımlamak üzere sızıntı sularının aktığ Deresi'nin Kızılırmak'a kavuştuğu yerin akış yönünün $30 \mathrm{~m}$ (Şekil 1'de; KS, Örnek-15'in) ilerisinden ve akışın tersi yönünde $30 \mathrm{~m}$ (Şekil 1'de; KÖ, Örnek-15'in) gerisinden su örnekleri alınmıştır. Bu örneklerde arazide, $\mathrm{pH}$, iletkenlik (EC), ORP (redox potansiyeli), çözünmüş oksijen miktarı (ÇO), tuzluluk, sıcaklık, atmosferik basınç (P) ölçümleri yapılmıştır (Çizelge 1, Şekil 3). Laboratuvarda ise su örnek noktalarında 5 litre'lik su örnekleri alınarak, su kimyası analizleri yapılmıştır. $\mathrm{Bu}$ örnekler ise kirlilik izlerini belirlemeye yönelik biyolojik oksijen içeriği (BOİ), kimyasal oksijen içeriği (KOI), toplam azot $(\mathrm{N})$, toplam klorür $\left(\mathrm{Cl}^{-}\right)$, toplam alkalinite ve bazı ağır metal $(\mathrm{Cu}, \mathrm{Hg}, \mathrm{Zn}$, $\mathrm{Fe}, \mathrm{Ni}, \mathrm{Cd}, \mathrm{Pb}$ ) analizleri yapılmıştır (Çizelge 2, Şekil 4).

\subsection{EMC (Electromagnetic Conductivity) Yöntem Çalışmaları}

Kayalardaki ya da topraktaki iletkenlik, bu birimlerin gözeneklerindeki elektrolitlerle sağlanır. İletkenliğin artmasında ya da azalmasında yerin elektriksel özdirenci, ortamdaki sıcaklık, basınç, gözeneklilik, geçirgenlik parametreleri ile ortamdaki iyonların devingenlikleri, derişimleri ve çözünme dereceleri de etkindir. Çevre jeofiziği araştırmalarında, deponi alanı sızıntı sularının kirlilik yayılımı EMC yöntemiyle de incelenmektedir. Çünkü deponi alanından yayılan sızıntı suları çok yüksek derişimlerde çözünmüş iyonlar içerirler. Bu iyonlar, belli bir orandan fazla yüzey ya da yeraltı sularına ve toprağa geçerse, su kaynakları ve toprak kirlenir. Bu kirleticilerden 
bazıları organik kirleticiler ve bazıları da ağır metaller olup, bunlar ortamın bileşimini değiştirirler. Yeraltı suyundaki ve topraktaki kirleticiler, ortamın iyon değişimini ve iletkenliğini arttırırlar ve kirli sulardaki mineraller içinden geçtiği kaya birimleri içinde de yayılarak, yüksek iletkenlikli alanlar oluşturabilirler. $\mathrm{Bu}$ durumda, yüzey sularında veya toprakta, sızıntı suları nedeniyle iletkenlik artar. $\mathrm{Bu}$ nedenle inceleme alanında yüksek iletkenlikli yerler EMC yöntemi ile incelenerek, yatay/düşey yöndeki sızıntı girişimi olan yüksek iletkenlikli alanlar su analizleri sonuçlarıyla karşılaştırılmıştır. Ancak, Özel [1] çalışmasından bu makale için sadece belli alanlardaki (A, B, E, D, G, H) EMC verilerini kullanmak yeterli olmuştur (Şekil 1). Bu veriler, jeofizik çalışma alanının kuzeyinde, tek profilli A-B alanlarının, daha güneyde ise derenin batısında E-D ve derenin doğusunda G-H alanlarındaki birden fazla profilden sadece ilk profile ait olan EMC verilerinden oluşmaktadır.

\section{BULGULAR}

\subsection{Arazi Su Kimyası Sonuçları}

Arazi deneyleri sadece yerinde (in-situ) su ölçümlerinden oluşmaktadır. Su örneği yerlerinde (ÇS, KS ve KÖ) Elmetron marka CX-701 çok fonksiyonlu arazi-laboratuvar ölçüm cihazı ile $\mathrm{pH}$, EC, tuzluluk, ORP, ÇO, sıcaklık ve P ölçümleri yapılmıştır (Çizelge 1, Şekil 3). Sızıntı suyu pH değerleri 8,3-8,5 aralığında olursa, alıcı ortam standartları için uygundur. Çizelge 1 ve Şekil 3 incelenirse, yıllık $\mathrm{pH}$ değerleri ÇS (en düşük Eylül-2009'da 8,03 ve en yüksek Haziran-2009'da $8,55)$ ve KS örneklerin (en düşük Ekim-2008'de 7,63 ve en yüksek Mart-2009'da 8,45) açısından karşılaştırılırsa, ÇS örnekleri pH değerleri çoğunlukla alıcı ortam standartlarında değildir. KS örneklerindeki yüksek değerler, yağışlarla süzülüp gelen veya eriyen karlarla gelen suların geçtikleri yerlerde bünyesine kattığı iyon içeriği ile ilişkili olarak bu aylarda yüksek olabilir. Diğer bir sonuç ise çözünmüş iyon içeriği ile ilişkili olarak ÇS örneklerindeki $\mathrm{pH}$ değerlerinin $\mathrm{KS}$ örneklerine göre daha bazik olmasıdır.

Çizelge 1 ve Şekil 3'e göre sızıntı suyunda ergimiş halde bulunan toplam tuz miktarının göstergesi olan EC değerleri ÇS örneklerinde, Aralık ayında $16,43 \mathrm{mS} / \mathrm{cm}$ ile en yüksek değere, Şubat ayında $5,22 \mathrm{mS} / \mathrm{cm}$ ile en düşük değere ulaşmaktadır. Genelde kurak dönemde artan EC değerlerine karşılık, yağışlı dönemdeki EC değerleri düşüktür. KS örneklerin EC değerlerinin de kurak dönemde yükseldiği ve Ağustos 2009'da 7,09 mS/cm ile en yüksek değerde olduğu ve yağışlı dönemde ise düştüğü ve Nisan 2009 'da $1,62 \mathrm{mS} / \mathrm{cm}$ ile en düşük değerde olduğu görülmektedir. EC değerlerindeki artışlar, kurak dönemde sıcaklık artışına bağlı olarak artan buharlaşmanın iyon içeriğini arttırması ile ilişkili olabilmektedir.

Çizelge 1. ÇS ve KS su örneklerinin arazi su kimyası sonuçları (-: Ölçülemedi) [1]

\begin{tabular}{|c|c|c|c|c|c|c|c|c|c|c|c|c|c|c|}
\hline \multirow{2}{*}{$\begin{array}{c}\begin{array}{c}\text { Arazi Su } \\
\text { Analizleri }\end{array} \\
\text { Aylar } \\
\end{array}$} & \multicolumn{2}{|c|}{$\mathbf{p H}$} & \multicolumn{2}{|c|}{$\begin{array}{c}\text { EC } \\
(\mathrm{mS} / \mathrm{cm})\end{array}$} & \multicolumn{2}{|c|}{$\begin{array}{c}\text { Tuzluluk } \\
(\%)\end{array}$} & \multicolumn{2}{|c|}{$\begin{array}{c}\text { ÇO } \\
(\%)\end{array}$} & \multicolumn{2}{|c|}{$\begin{array}{c}\text { Sicaklık } \\
\left({ }^{\circ} \mathrm{C}\right)\end{array}$} & \multicolumn{2}{|c|}{$\begin{array}{l}\text { ORP } \\
(\mathbf{m V})\end{array}$} & \multicolumn{2}{|c|}{$\begin{array}{c}\text { Basınç } \\
\text { (atm) }\end{array}$} \\
\hline & ÇS & $\mathrm{KS}$ & ÇS & $\mathrm{KS}$ & ÇS & $\mathrm{KS}$ & ÇS & $\mathrm{KS}$ & ÇS & KS & ÇS & $\mathrm{KS}$ & ÇS & $\mathrm{KS}$ \\
\hline Ekim 2008 & 8,21 & 7,63 & 11,65 & 3,92 & 7,8 & 2,6 & - & - & 18,48 & 18 & - & - & 867 & 868 \\
\hline Kasım 2008 & 8,26 & 8,23 & 13,26 & 4,40 & 8,9 & 2,95 & 1,4 & 2,4 & 18 & 18 & - & - & 867 & 867 \\
\hline Aralık 2008 & 8,18 & 8,15 & 16,43 & 4,14 & 11,0 & 2,8 & 27,5 & - & $-0,34$ & $-0,4$ & - & - & 875 & 876 \\
\hline Ocak 2009 & 8,14 & 8,06 & 8,16 & 3,73 & 5,5 & 2,5 & 57,5 & 57,0 & 2 & 2 & - & - & 871 & 871 \\
\hline Şubat 2009 & 8,16 & 8,03 & 5,22 & 2,28 & 3,5 & 1,52 & 86,0 & 94,8 & 2,45 & 2,66 & -64 & $-74,9$ & 868 & 869 \\
\hline Mart 2009 & 8,38 & 8,45 & 7,36 & 3,55 & 4,9 & 2,37 & 47,0 & 60,5 & 8 & 8,2 & $-74,5$ & $-79,1$ & 866 & 867 \\
\hline \begin{tabular}{|l|} 
Nisan 2009 \\
\end{tabular} & 8,18 & 8,20 & 7,47 & 1,62 & 5,0 & 1,08 & 45,0 & 65,3 & 14,56 & 14,33 & $-72,5$ & $-75,0$ & 868 & 868 \\
\hline Mayıs2009 & 8,30 & 8,30 & 6,95 & 2,25 & 4,6 & 1,5 & 66,5 & 66,8 & 17,6 & 14,79 & $-72,6$ & $-72,6$ & 867 & 868 \\
\hline Haziran 2009 & 8,55 & 8,35 & 7,57 & 3,61 & 5,07 & 2,42 & 93,8 & 74,4 & 19,14 & 18,4 & $-68,0$ & $-56,1$ & 872 & 873 \\
\hline Temmuz 2009 & 8,29 & 8,13 & 10,00 & 5,70 & 6,7 & 3,82 & 36,3 & 78,5 & 19,6 & 18,3 & $-78,2$ & $-55,6$ & 871 & 872 \\
\hline Ăgustos 2009 & 8,43 & 7,95 & 8,05 & 7,09 & 5,4 & 4,75 & 75,5 & 75,1 & 17 & 17 & $-78,8$ & $-54,5$ & 873 & 874 \\
\hline Eylül 2009 & 8,03 & 7,75 & 8,30 & 6,57 & 5,56 & 4,4 & 46,5 & 54,0 & 17,02 & 19 & $-64,9$ & 49,0 & 877 & 876 \\
\hline
\end{tabular}


ÇO’nin doğal veya atık sulardaki derişimi, fiziksel, kimyasal ve biyokimyasal faaliyetlere bağlıdır. Aeorobik ortamda yaşayan organizmaların çoğalmalarında ve bunların enerji üreten metabolik faaliyetlerinde ÇO'e gerek duyulur. ÇO miktarının $\%$ olarak ÇS örneklerinde Şubat ve KS örneklerinde Temmuz ayında en yüksek değere ulaştığı görülür ve bu aylar dışında genel olarak birbirine koşuttur (Çizelge 1, Şekil 3).

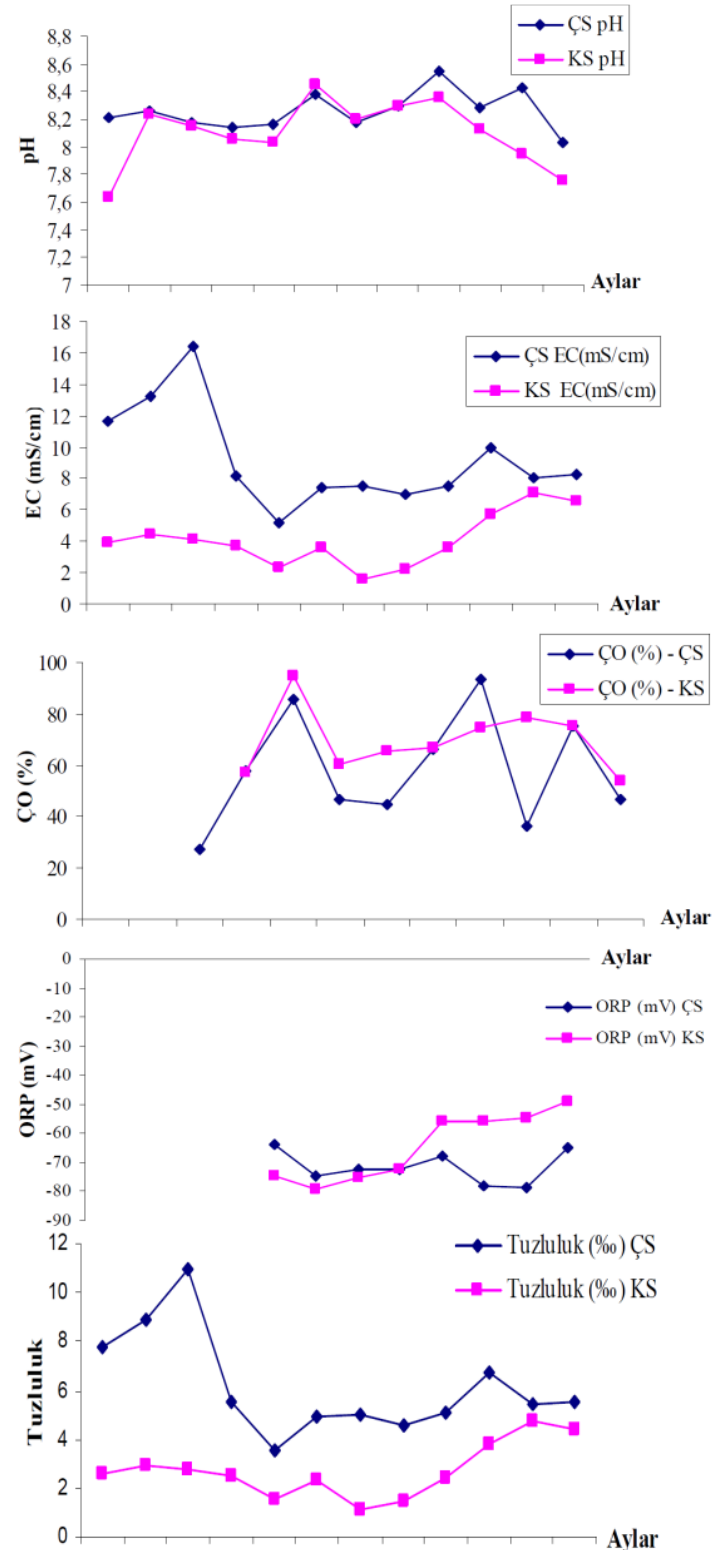

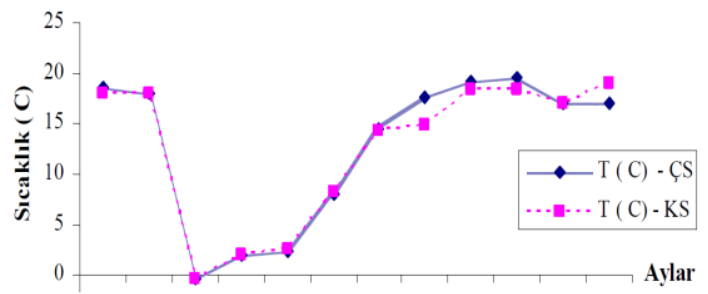
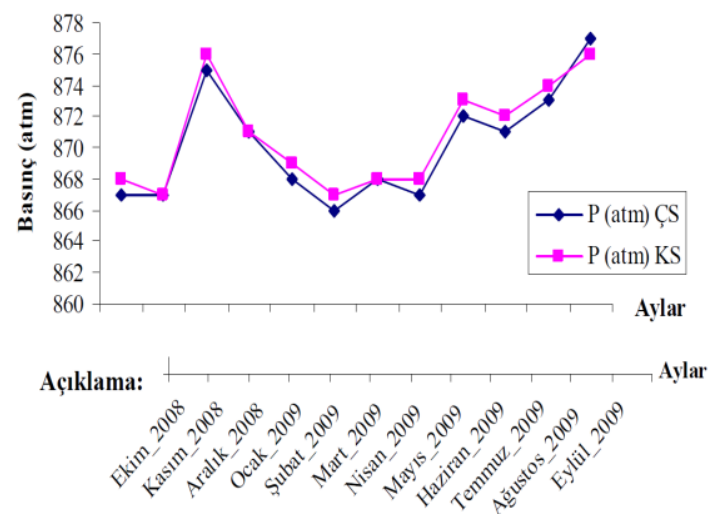

Şekil 3. ÇS ve KS örneklerinin yıllık arazi su kimyası sonuç grafikleri [1]

Ayıca, ÇS kurak dönem değerleri değişken bir yapı göstermektedir. Temiz su yaklaşık olarak \%60-80 arasında oksijen içerirken, kirli sular (atık su) genellikle oksijence zayıftır. ÇS değerlerinde ÇO miktarı Mayıs ayında \%66,5 ve Ağustos ayında $\% 75,5$ olup, diğer aylarda \%60-80 aralığındaki değerlerden ya daha düşük yada daha yüksektir. KS örneklerde ise Mart-Ağustos ayları arasında \%60-80 aralığında, bu aylar dışında ise düşük ya da yüksek değerlerde olduğu görülmektedir. Buna göre, KS örnekleri çoğunlukla temiz su olma koşullarını sağlamaktadır. ÇO’in sudaki derişimi, sıcaklık ve tuzluluğun fonksiyonu olup, arasında ters orantı vardır. ÇO değerlerinin artmasına karşılık, sıcaklık ve tuzluluk değerlerinin düşmesi gerekir. Grafikler genel olarak uyumludur. ORP değerleri incelenirse, ÇS-ORP değerleri y1llık-64,0 ile $-78,8 \mathrm{mV}$ değerleri arasında değişmekte olup, Temmuz ve Ağustos aylarında en yüksektir. KSORP değerleri -49,0 ile 79,1 mV değerleri arasında değişmekte olup, Mart ayında en yüksektir. ÇS için y1llık ortalama ORP değeri $-71,69 \mathrm{mV}$ ve $\mathrm{KS}$ için $-64,59 \mathrm{mV}$ 'tur. Negatif ORP (-mV) değerleri, sudaki mineral içeriğinin yüksek olduğunun ve 
organik ayrışma için oksidasyon gücünün azaldığının göstergesidir. $\mathrm{Bu}$ nedenle ve genel olarak pH değerleri de yüksek ise ÇS ve $\mathrm{KS}$ için suda anaerobik bir ortam olduğu söylenebilir. ÇS ve KS için Şubat-Mayıs arasındaki yağışlı dönemde ORP değerlerinde artış gözlenirken, sıcaklıkların en üst değerlere çıktığı Haziran-Eylül arasındaki kurak dönemde ÇS'nda ORP artmakta, KS'nda ise kurak dönemde düşmektedir. ORP değerleri, suda oksijen azalmasına bağlı olarak azalır ve bu durum genel olarak kurak dönemde görülmektedir (Çizelge 1, Şekil 3).

ÇS ve KS grafiklerinde atmosferik basınç değerleri yıl boyunca birbirine paraleldir. ÇS noktasında ölçülen atmosferik basınç değerleri, kot farkından (yaklaşık $20 \mathrm{~m}$ ) dolayı KS noktasındaki değerlere göre daha düşüktür. Yükseklik arttıkça basınç düşeceğinden, yıllık ortalama basınç değeri ÇS noktasında (yaklaşık 1285 m'de) 870 atm ve KS noktasında (yaklaşık 1265 m'de) ise 871 atm'dir. Ayrıca tuzların çözünürlüğü, genelde (bazı tuzlar hariç) sıcaklıkla veya ise belli bir sıcaklığa kadar artar ve bu değerden sonra azalabilir. Oksijen ise suda çok az çözünen bir gazdır ve çözünürlüğü verilen sıcaklıkta atmosfer basıncı ile doğrudan değişir. Ancak su örnek noktalarının birbirlerinden çok uzakta olmaması sebebiyle genel olarak bu sularda çözünürlüğü etkileyen ölçüde bir basınç farkı yoktur. ÇO, tuzluluk, sıcaklık ve basınç arasındaki ilişkiler birlikte irdelenirse ÇO artışının, basınçla doğru, sıcaklıkla ters orantılı olarak değiştiği görülür. ÇO miktarı arttıkça, basınç da artmakta, bunlara karşılık sıcaklık ise düşmektedir. Tuzluluk ise ÇS için sıcaklık arttıkça artmaktadır. Ancak sıcaklık-tuzluluk ilişkisi KS için değişken bir yapı sunar.

\subsection{Laboratuar Su Kimyası Sonuçları}

Laboratuvar çalışmasında ÇS, KS ve KÖ sulardan örneklerinde, BOI, KOI, toplam alkalinite, toplam azot, toplam klorür, ağır metal (Fe, $\mathrm{Pb}, \mathrm{Ni}, \mathrm{Zn}, \mathrm{Cu}$, $\mathrm{Cd}, \mathrm{Hg}$ ve $\mathrm{Cr}$ ) analizleri yapılmıştır (Çizelge 2, Şekil 4). ÇS ve KS su örnekleri, bir yıllıktır. KÖ su örnekleri ise Kasım 2008 ve Şubat-Haziran-Eylül 2009 aylarını kapsamaktadır.

Genellikle temiz veya az kirli sularda BOİ, KOİ'nin \%50'si kadar olup, bu değerden düşük olursa, ortamda zehirlilik yüksek olur. Çizelge 2 ve Şekil 4'de, ÇS örneklerinde BOI $_{5}$ değerleri 79-675 $\mathrm{mg} / \mathrm{L}$ ve KOI değerleri ise 381,6-2537,6 mg/L arasında değişmekte ve genelde en yüksek değerler Ekim 2008 ile Ocak 2009 ayları arasındadır. ÇS örneklerinde, BOI değerleri, KOI değerlerinin \%50'sinden düşük olup, BOI (>100 mg/L) ile KOI $(>160 \mathrm{mg} / \mathrm{L})$ değerleri deşarj standartlarının üzerinde olduğu için ÇS yüksek oranda zehirlidir. $\mathrm{KS}$ örneklerde ise $\mathrm{BOI}_{5}$ değerleri $0-83 \mathrm{mg} / \mathrm{L}$ arasında ve KOI değerleri 8,8-195,2 mg/L arasında değişmekte olup, en yüksek değerler Ocak-ŞubatMart aylarındadır ve çok az bir kirleme vardır. Sızıntı suyundaki BOI/KOI oranları ise biyolojik olarak arıtılabilirliği yansıtır. Yeni sularda bu oran 0,5 dolayındadır ve eski sularda 0,2'lerde olup, daha duraylı hale gelir. Bu oranın yüksek çıkması fazla miktarda organik madde bulunduğunun göstergesi olabilir. Bu oran ÇS örneklerinde 0,180,46 arasında değişmektedir. Özellikle Şubat ayında $\mathrm{BOI} / \mathrm{KOI}$ oranının 0,18 değerine düşmüş olması ve ortalama BOI/KOI oranının 0,29 olması, ÇS örneklerinde organik madde miktarının fazla ve duraysız olduğunu, ÇS'nun genç ve biyolojik olarak arıtılabilir olduğunu gösterir. KS örneklerdeki BOI/KOI oranları ise 0,05-0,51 arasında değişir, Aralık ve Eylül ayında BOI/KOI oranı, 0,05 değerine kadar düşer ve ortalama $\mathrm{BOI} / \mathrm{KOI}$ oranı 0,26 'dır. $\mathrm{Bu}$ verilere göre, Kızılırmak'a çok az organik madde karışmaktadır.

ÇS değerlerinde Aralık ayında toplam alkalinite $3350 \mathrm{mg} / \mathrm{L}$, toplam klorür 3253,32 mg/L ve toplam azot $622,48 \mathrm{mg} / \mathrm{L}$ en yüksektir. Toplam alkalinite Ocak ayında $1050 \mathrm{mg} / \mathrm{L}$ ile toplam klorür Mayıs ayında $893,34 \mathrm{mg} / \mathrm{L}$ ile ve toplam azot Ağustos ayında $183 \mathrm{mg} / \mathrm{L}$ ile en düşük değerdedir. ÇS ve KS örneklerinde toplam baziklik, toplam klorür ve toplam azot eğrileri yaklaşık aynı yönde değişmekte olup, bu durum özellikle Mart ve Ağustos ayları arasında gözlenmektedir. 
Çizelge 2. ÇS ve KS için laboratuvar su kimyası sonuçları (-: Ölçülemedi. TEDB: Tespit edilebilir düzeyde değil. Bazı sonuçlar ve KÖ sonuçları, standartların altında olup, eklenmemiştir) [1]

\begin{tabular}{|c|c|c|c|c|c|c|c|c|c|c|c|c|}
\hline \multirow{3}{*}{$\begin{array}{l}\text { Laboratuar Su Analizleri } \\
\text { ÇS analizleri }\end{array}$} & \multicolumn{12}{|c|}{ Aylara Göre } \\
\hline & \multicolumn{3}{|c|}{2008 yilı sonuçları } & \multicolumn{9}{|c|}{2009 yllı sonuçları } \\
\hline & Eki & Kas & Ara & Oca & Şub & Mar & Nis & May & $\mathrm{Haz}$ & Tem & Ağgu & Eyl \\
\hline $\mathrm{BOI} \mathrm{mg} / \mathrm{L}$ & 675 & 510 & 770 & 445 & 265 & 580 & 115 & 120 & 90 & 275 & 125 & 79 \\
\hline KOİ mg/L & 2502 & 1851,2 & 2537,6 & 965,12 & 1472 & 1307 & 631 & 563,2 & 334,56 & 998,4 & 601,92 & 381,6 \\
\hline BOI/KOI oranları & 0,27 & $\mathbf{0 , 2 7 5 5}$ & 0,3034 & 0,4611 & 0,18 & 0,4438 & 0,182 & 0,213 & 0,269 & 0,27544 & 0,207669 & $\mathbf{0 , 2 0 7}$ \\
\hline \multicolumn{13}{|l|}{ Toplam alkalinite } \\
\hline $\mathrm{mg} \mathrm{CaCO}_{3} / \mathrm{mL}$ & 2850 & 2850 & 3350 & 1050 & 1100 & 1650 & 1300 & 1300 & 1200 & 1650 & 1300 & 1500 \\
\hline Toplam azot mg/L & 536,9 & 441,05 & 622,48 & 622,48 & 111,4 & 217,2 & 189,7 & 192,5 & 221,6 & 220 & 183 & 240 \\
\hline Klortir mg/L & 3191 & 2895,5 & 3253,2 & 1281,6 & 1058,9 & 1127,6 & 1040 & 893,3 & 1007 & 1163,9 & 1081,9 & 1216,6 \\
\hline $\mathrm{Ni} \mathrm{mg/L}$ & 0,16 & 0,13 & 0,25 & 0,2 & 0,155 & 0,87 & 0,09 & 0,09 & 0,07 & 0,1 & 0,1 & 0,06 \\
\hline $\mathrm{Zn} \operatorname{1rig} / \mathrm{L}$ & 0,03 & 0,04 & 0,11 & 0,04 & 0,02 & 0,05 & 0,6 & 0,03 & 0,01 & 0,04 & 0,19 & 0,04 \\
\hline $\mathrm{Fe} \mathrm{mg/L}$ & 0,9 & 0,61 & 1,15 & 0,8 & 0,57 & 0,98 & 0,61 & 0,42 & 0,34 & 0,59 & 0,47 & 0,56 \\
\hline $\mathrm{Mg} \mathrm{mg} / \mathrm{L}$ & - & - & - & - & - & 184,6 & 139,1 & 125,6 & 185,7 & 192 & 160,5 & 165,4 \\
\hline $\mathrm{Ca} \mathrm{mg/L}$ & - & - & - & - & - & 248,3 & 86,7 & 83,1 & 213,3 & 124,1 & 181,5 & 134,3 \\
\hline KS analizleri & Eki & Kas & Ara & Oca & Şub & Mar & Nis & May & Haz & Tem & Ăğu & Eyl \\
\hline BOİ mg/L & 1 & 5 & 1 & 54 & 55 & 83 & 1 & 4 & 5 & 28 & 5 & 4 \\
\hline KOİ mg/L & 14,72 & 14,24 & 19,52 & 139,2 & 147,2 & 195,2 & 9,28 & 8,8 & 9,84 & 96 & 54,72 & 76,32 \\
\hline BOI/KOI oranları & 0,068 & 0,3511 & 0,0512 & 0,3879 & 0,3736 & 0,4252 & 0,108 & 0,455 & 0,5081 & 0,29167 & 0,091374 & 0,0524 \\
\hline \multicolumn{13}{|l|}{ Toplam alkalinite } \\
\hline $\mathrm{mg} \mathrm{CaCO}_{3} / \mathrm{mL}$ & 211 & 192 & 197 & 284 & 310 & 443 & 182 & 174 & 200 & 341 & 168 & 518 \\
\hline Toplam azot mg/L & 23.67 & 11.6 & 2,33 & 2,33 & 23,9 & 50,86 & TEDB & 0,96 & 5,02 & 4,9 & 6,5 & 16,9 \\
\hline Klorür $\mathrm{mg} / \mathrm{L}$ & 956,7 & 825,2 & 850,87 & 631,7 & 361,5 & 369,25 & 123,1 & 178,7 & 468,83 & 468,83 & 952,9 & 871 \\
\hline $\mathrm{Ni} \mathrm{mg/L}$ & 0,01 & 0,01 & TEDB & 0,03 & 0,02 & 0.02 & TEDB & TEDB & TEDB & 0,01 & TEDB & 0,05 \\
\hline $\mathrm{Zn} \mathrm{mg/L}$ & TEDB & 0,02 & 0,1 & 0,02 & 0,11 & 0,02 & 0,01 & 0,01 & TEDB & 0,02 & TEDB & TEDB \\
\hline $\mathrm{Fe} \mathrm{mg/L}$ & 0,25 & 0,04 & 0,01 & 0,4 & 0,03 & 0,12 & 0,01 & 0,05 & TEDB & 0,04 & TEDB & 0,03 \\
\hline $\mathrm{Mg} \mathrm{mg} / \mathrm{L}$ & - & - & - & - & - & 51,5 & 15,2 & 15,1 & 23,9 & 47,3 & 32 & 78,5 \\
\hline $\mathrm{Ca} \mathrm{mg/L}$ & - & - & - & - & - & 211,2 & 70,6 & 78,1 & 233 & 291,1 & 372,8 & 212,4 \\
\hline
\end{tabular}

ÇS ve KS örneklerinde az sayıda ağır metal için yapılan analizlerde $\mathrm{Fe}, \mathrm{Ni}, \mathrm{Zn}$ ve $\mathrm{Cu}$ ağır elementlerine rastlanmıştır. Fe, derişimi en yüksek ağır metal olup, Fe derişimi ÇS için 0,34-1,15 $\mathrm{mg} / \mathrm{L}$ değişmektedir ve $\mathrm{KS}$ için $0,87 \mathrm{mg} / \mathrm{L}$ 'den azdır. Diğer ağır metallerin derişimleri çoğunlukla alıcı ortam standartlarına uygundur. KS örneklerde de rastlanan bu ağır metallerin derişimleri, ÇS örneklerine göre oldukça düşüktür. Ancak ÇS ve KS örneklerindeki kirlilik değişkenlerinin, riskli derişimlere ulaştığ görülür. Arazi ve laboratuvar analizleriyle çevre ve canlı yaşamı için zararlı derişimlerdeki organikinorganik maddeler, ÇS ve KS örneklerinde belirlenmiştir. KÖ su örnekleri mevsimlik olup, yağışlı ve kurak dönemi yansitacak aylara aittir [1]. KÖ örneklerde çöp kaynaklı kirletici bulunmadığından, bu sulardaki bileşenlerin KS suların derişimlerini arttırıp arttırmadığ 1 incelenmiş ve riskli bir durum belirlenmemiştir.

Bu sonuçlar, [12]'nin su kimyası sonuçlarıyla da karşılaştırılmıştır [1]. 5 yıl önceki su kimyası sonuçlarına göre, kirletici derişimlerinde önemli miktarda azalma olmasına rağmen, kirletici derişimlerinin hala standartların çok üzerinde olduğu anlaşılmıştır.
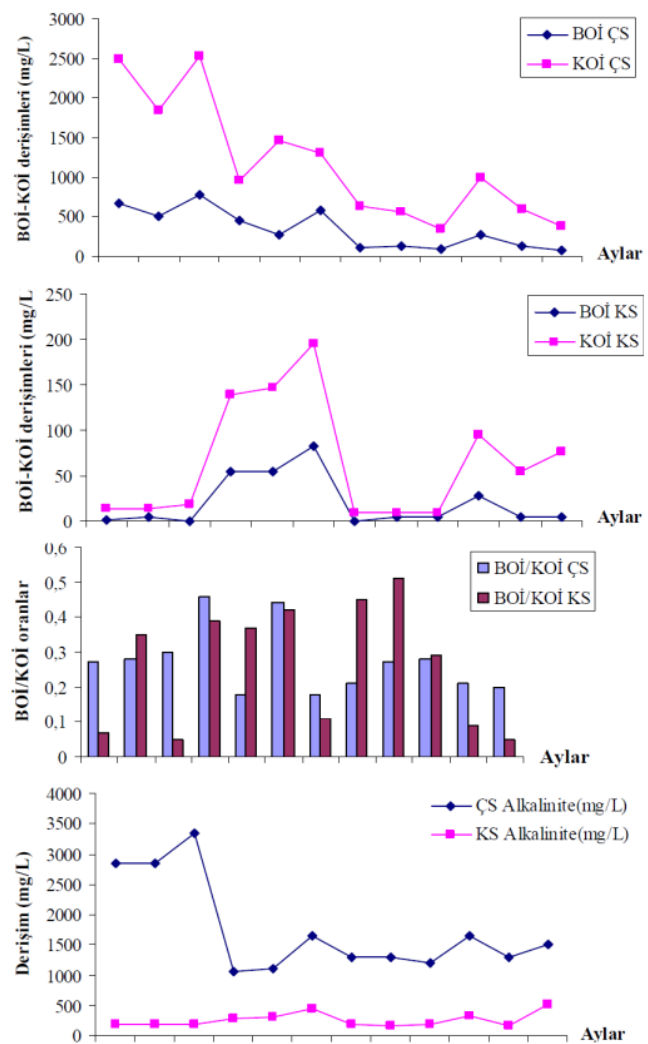

Şekil 4. ÇS ve KS örneklerinin yıllık laboratuar su kimyası sonuç grafikleri [1] 

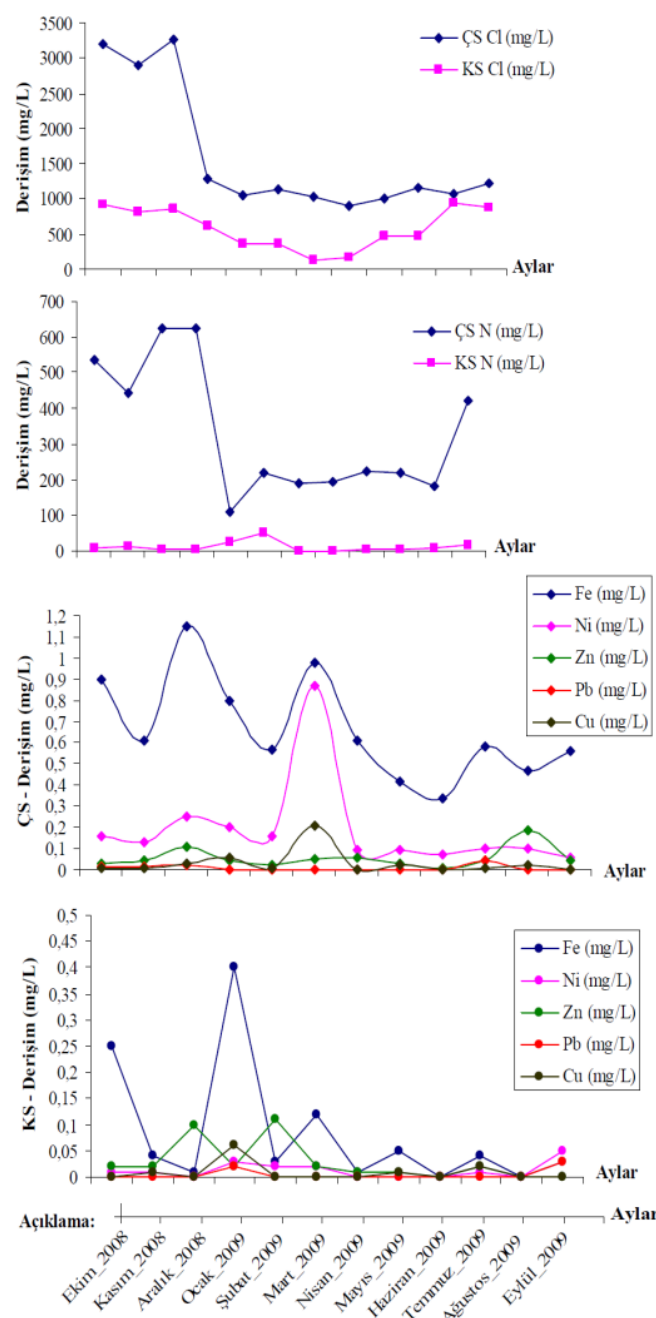

Şekil 4. (devamı)

\subsection{EMC Ölçülerinin Sonuçları}

EMC yönteminde yerin iletkenliği doğrudan ölçülerek, görünür elektromanyetik iletkenlik ölçüleri olarak kaydedilirler. EMC ölçümlerinde 9,76 kHz frekansinda sinyal üreten GF-Instrument firmasının EM-CMD4 model cihazı kullanılmıştır. EMC profilleri Haçin deresi boyuca ayrı alanlarda, genelde doğu-batı yönlü olarak ve profil boyunca sabit bir hızla yürüyerek alınmıştır. Bu ölçüler, Surfer programında değerlendirilerek, görünür iletkenlik grafikleri elde edilmiştir (Şekil 5 ve Şekil 6). EMC cihazı ile yüksek frekansta ölçü alındığından, EMC grafikleri yalnızca yüzeye yakın bilgileri içerir. Bu nedenle görünür iletkenlik grafikleri ilk 1,5 m derinlik için duyarlıdır.
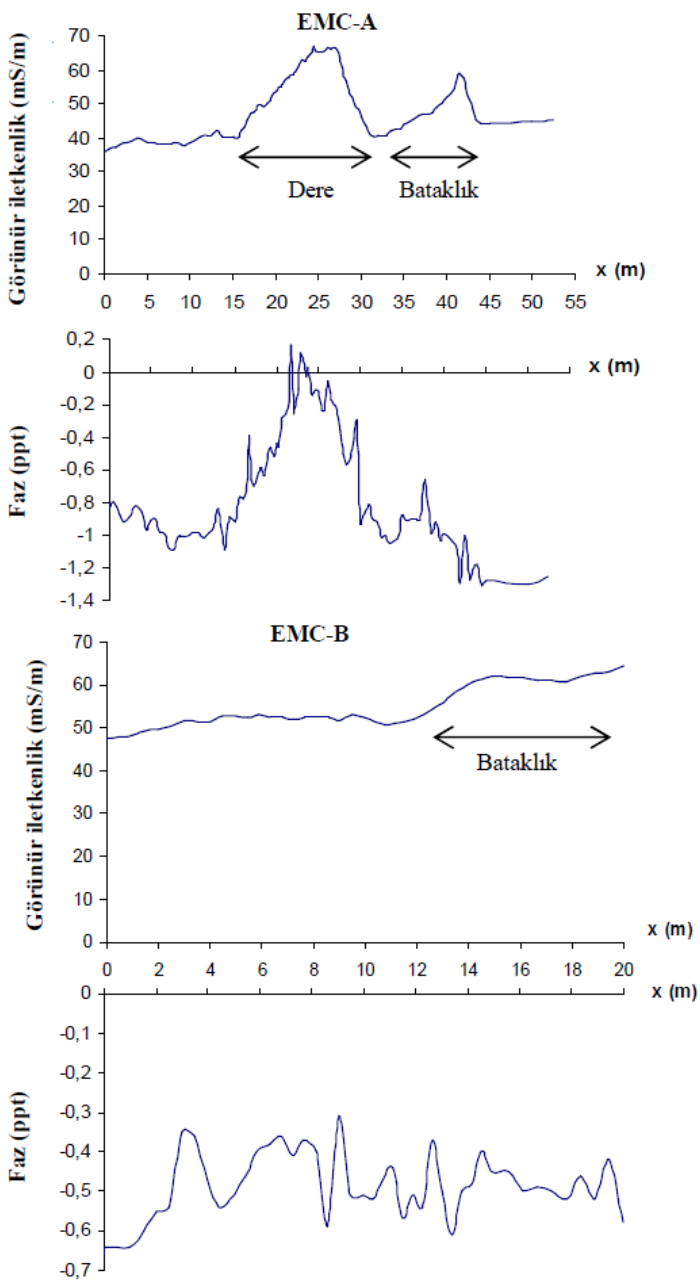

Şekil 5. EMC-A ve EMC-B profillerinin görünür iletkenlik ve faz grafikleri

İlk görünür iletkenlik ölçüsü sızıntı suyu deşarj notasının hemen $10 \mathrm{~m}$ güneyinde yaklaşık doğubatı yönlü (K20B) olarak A alanında alınmıştır (Şekil 1). Bu alandaki EMC-A profilinin boyu 55 m'dir ve profil dereyi yaklaşık dik kesmektedir (Şekil 5). EMC-A profilinin grafiği incelenirse, profilde 15-30 m'ler arasında yüksek iletkenlik değerlerinin yaklaşık $35-65 \mathrm{mS} / \mathrm{m}$ aralığında ve 40-45 m'ler arasında ise yaklaşı $40-60 \mathrm{mS} / \mathrm{m}$ 
aralığında değişmekte olduğu görülür. EMC-A profilinin yaklaşık $50 \mathrm{~m}$ güneyinde ve Haçin deresinin doğu tarafinda ise B alanı bulunmaktadır (Şekil 1). Bu alanda, 20 m'lik yaklaşık kuzeydoğugüneybatı yönlü olan EMC-B profilinin ölçüsü alınmıştır (Şekil 5). EMC-B profili, menderes morfolojisi nedeniyle hem dereye yaklaşık paraleldir, hem de dereyi yaklaşık dik kesmektedir. EMC-B grafiği incelenirse, genelde 10 m'ye kadar az bir artış olmakla birlikte iletkenlik 10 m'de $54 \mathrm{mS} / \mathrm{m}$ değeri göstermektedir. Ancak iletkenlik 10 m'den sonra azalmakta (yaklaşık 50-52 mS/m) ve yaklaşık $12 \mathrm{~m}$ 'den sonra tekrar ve daha yüksek bir düzeyde olup, yaklaşık 52-65 mS/m aralığında değişerek artmaktadır (Şekil 5). İnceleme alanının daha güneyinde ise $\mathrm{E}, \mathrm{D}, \mathrm{G}$ ve $\mathrm{H}$ alanlarında diğer profillerin (EMC-E, EMC-D, EMC-G ve EMC-H) ölçüleri alınmıştır (Şekil 1, Şekil 6). Bu profiller 20-25 m'liktir ve profil başlangıçları dereden başlamaktadır. Grafiklerde, dereden uzaklaştıkça iletkenlik değerlerinin giderek azaldığı ve faz grafikleri ile de uyumlu oldukları anlaşılmıştır.

Sonuç olarak görünür iletkenlik grafikleri iletkenliğin, kirli alanlarda yaklaşık $35 \mathrm{mS} / \mathrm{m}$ 'den daha yüksekte, kirliliğin en yoğun olduğu alanlarda ise $70 \mathrm{mS} / \mathrm{m}$ değerine yaklaştığını göstermiştir. A alanındaki kirliliğin (ilk deşarj yerinde) dereye yakın alanlarda ve diğer alanlara (B, E, D, G, H) göre en yüksek değerlerde olduğu ve diğer alanlarla karşılaştırıldığında ise yani güneye doğru ilerledikçe, iletkenlik değerlerinin düştüğü ve dereden uzaklaştıkça da daha düşük iletkenlikli alanlar olduğu anlaşılmıştır. Bu durumlar kirliliğin, yüzeydeki geçirimli jeolojik birim boyunca doğuya doğru ve güneydoğu yönlü olarak yayıldığını ve sıvıdaki katıların birimde ilerlerken tutunmaları nedeniyle dereden uzaklaştıkça azaldığını da göstermektedir. $\mathrm{Bu}$ azalmanın, Kızılırmak'a doğru yaklaşık \% 30 olduğu hesaplanmıştır. Bu azalma zaman zaman yağışlar nedeniyle seyrelme olayı olmasından da kaynaklanabilir. Ancak bu azalıma rağmen, su kimyası sonuçları organik-inorganik kirleticilerin standartların üzerinde olduğunu, toprağı kirlettiğini ve bu kirleticilerin Kızılırmak nehrine de karıştığını göstermiştir. Ayrıca, ilk deşarj alanından Kızılırmak nehrine yaklaştıkça iletkenlik değerleri düşmüş olsa bile kirletici varlığının hala yüksek standartlarda olması önemlidir.
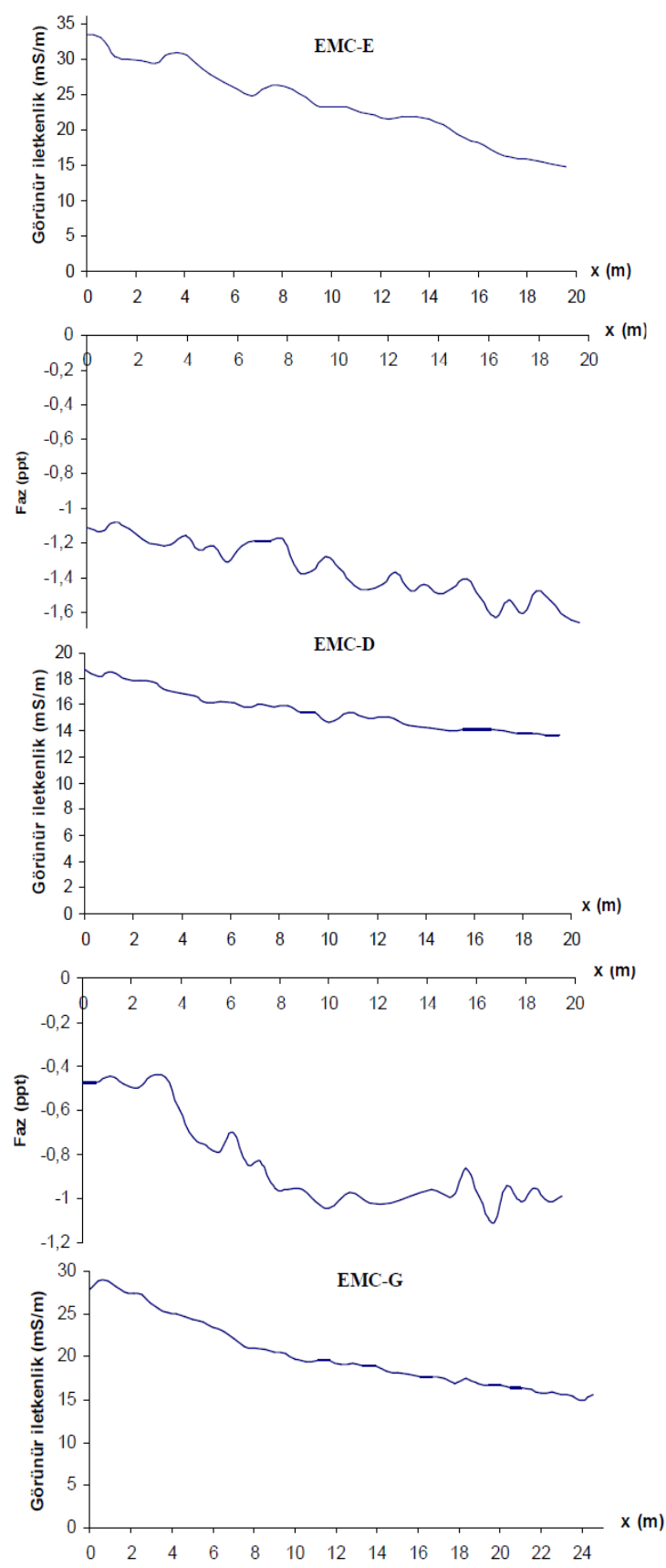

Şekil 6. Jeofizik çalışma alanı güneyindeki EMC profillerinin görünür iletkenlik ve faz grafikleri 


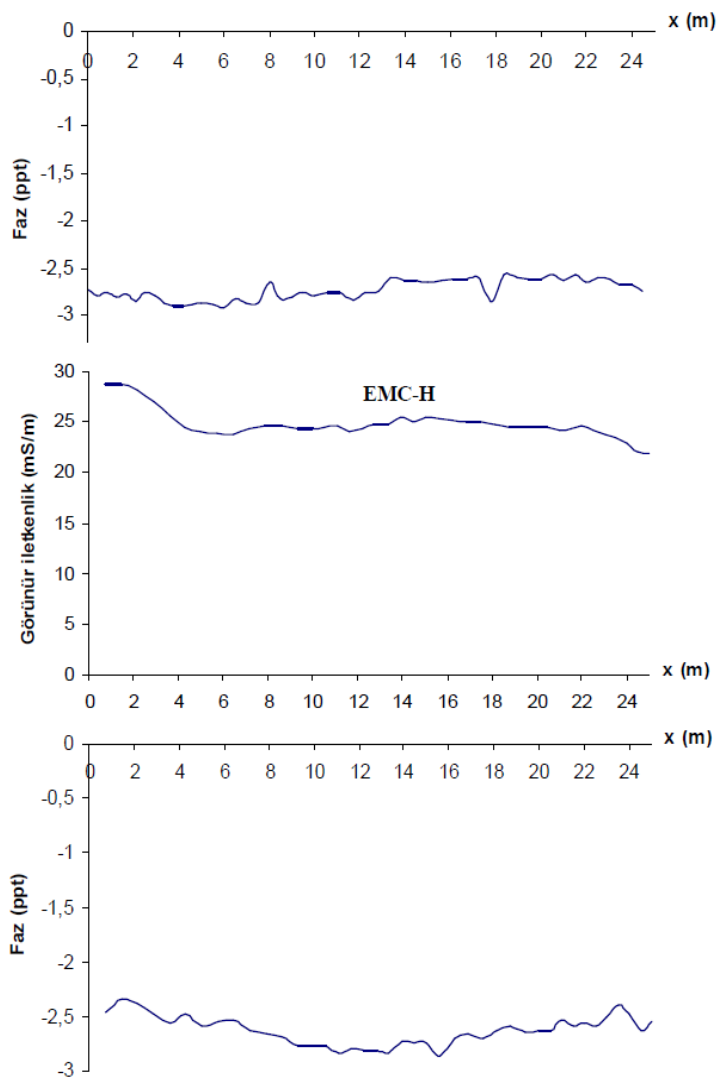

Şekil 6. (devamı)

$\mathrm{Bu}$ kirli yada kısmen kirli alanlarda görünür iletkenlik değerlerinin yüksek olmasında jeolojik birimin geçirimli ve jeolojik tabakalanmanın güneye doğru eğimli olmasının yanı sıra sızıntı suyunun dere boyunca akmaya devam ediyor olmasıyla da ilişkili olduğu anlaşılmıştır.

Alanda yapılan diğer jeofizik ve jeolojik çalışmalarla yeraltısuyu seviyesinin yüksek olduğu ve jeolojik birimin geçirimli olduğu bilindiğinden, bu kirleticilerin yeraltı sularına karıştığı da unutulmamalıdır.

\section{SONUÇLAR VE ÖNERÍLER}

İnceleme alanında oluşan çevresel kirliliğin (suda ve toprakta), deponi alanındaki çöp sızıntı sularından kaynaklandığı ve sızıntı sularındaki organik-inorganik kirleticilerin önce toprağa, daha sonra yöredeki yeraltı ve yüzey sularına
(Kızılırmak nehrine) taşındığı su kimyası ve jeofizik çalışmalarla kanıtlanmıştır. Arazi ve laboratuar su analizleri, anaerobik koşulların bulunduğunu, ama ÇS su örneklerinde KS örneklerine göre çok yüksek olduğunu ve KS örneklere nehir suyunun karışmasıyla seyrelme olduğunu ve bu seyrelmenin çoğunlukla Kızılırmak'a ulaştıktan sonra gerçekleştiğini göstermiştir. Jeofizik yorumlamada, EMC grafiklerinden görünür iletkenliğinin yüksek (ortalama $>25 \mathrm{mS} / \mathrm{m}$ ) olduğu yerlerin, sızınt1 sularıyla kirlenmiş, daha düşük iletkenlikli (ortalama $<18-25 \mathrm{mS} / \mathrm{m}$ ) yerlerin ise toprakta tutunma nedeniyle, ileri kirlilik kaynağından uzaklaştıkça kirli ama daha az kirlenmiş alanlar olduğu anlaşılmıştır [6]. Ayrıca kuzeyden güneye doğru toplam kirletici miktarlarının yaklaşık \%30 oranında azaldığı hesaplanmış ve buna rağmen kirletici miktarlarının hala standartların üzerinde olduğu anlaşılmıştır.

Sonuç olarak, toprak ve yüzey sularını tehdit eden bu sızıntı sularının, yağışsız dönemlerde kuru olan Haçin Deresi'ni izleyerek yüzey suyu ve/veya yüzey altı akımı şeklinde Kızılırmak'a ulaştığı anlaşılmıştır. Düzenli deponi alanına geçmek için yapılan havuz inşaatlarının henüz tamamlanmadığı da dikkate alınırsa, bölgede sızıntı sularının çevre etkileri devam edecektir. Bu nedenle bir tarafta, oluşan sızıntı suları kirliliği izlenirken, diğer tarafta sızıntı sularının ÇED süreci çerçevesinde denetimi için çaba harcanmalıdır.

\section{TEŞEKKÜR}

$\mathrm{Bu}$ çalışma, Cumhuriyet Üniversitesi Bilimsel Araştırma Projeleri Komisyonu tarafindan M-352 numaralı CÜBAP Projesi olarak desteklenmiştir.

\section{KAYNAKLAR}

1. Özel, S., 2010. Sivas İli Katı Atık Depolama Alanında Sizıntı Suyunun Yeraltındaki Yayılımının Jeofizik Yöntemlerle İncelenmesi. Doktora Tezi, Cumhuriyet Üniversitesi, 148.

2. Nobes, D.C., Armstrong, M.J., Close, M.E., 2000. Delineation of a Landfill Leachate Plume 
and flow Channels in Coastal Sands Near Christchurch, New Zealand, using a Shallow Electromagnetic Survey Method. Hydrogeology Journal, 8(3), 328-336.

3. Karlık, G., Kaya, M.A., 2001. Investigation of Groundwater Contamination using Electric and Electromagnetic Methods at an Open Wastedisposal Site: A Case Study from Isparta, Turkey. Environmental Geology, 40(6), 725-731.

4. Rucker, D.F., Sweeney, M.D., 2004. Plume Delineation in the BC Cribs and Trenches Area. PNNL-14498, Pacific Northwest National Laboratory, Richland, WA.

5. Kaya, M.A., Özürlan, G., Şengül, E., 2007. Delineation of Soil and Groundwater Contamination using Geophysical Methods at a Waste Disposal Site in Çanakkale, Turkey. Environmental Monitoring Assessment, 135(3), 441-446, 2007.

6. Özel, S. Yılmaz, A., Candansayar, M. E., 2017. The Examination of the Spread of the Leachates Coming out of a Solid Waste Disposal area on the Ground with Geophysical and Geochemicalmethods (Sivas, Turkey). Journal of Applied Geophysics, 138, 40-49.

7. Aaltonen, J., 1998. The use of Direct Current Methods in Landfill Investigations-a Study on Glaciated Terrains. Licentiate Thesis, Royal Institute of Technology, Stockholm, TRITAAMI LIC 2025.

8. Aaltonen, J., Olofsson, B., 2001. Direct Current (DC) Resistivity Measurements in Long-term Groundwater Monitoring Programmes. Environmental Geology, 41, 662-671.

9. Olofsson, B., Jernberg, H., Rosenqvis, A., 2006. Tracing Leachates at Waste Sites using Geophysical and Geochemical Modelling. Environmental Geology, 49, 720-732.

10. Rucker, D.F., Fink, J.B., 2007. Inorganic Plume Delineation using Surface HighResolution Electrical Resistivity at the BC Cribs and Trenches Site, Hanford. Vadose Zone Journal, 6(4), 946-958.

11. Sivas Belediyesi, 2005. Sivas Belediyesi Çevresel Etki Değerlendirme Raporu (yayınlanmamıs), 90.
12. Atmaca, E., 2004. Sivas İl Merkezinin Kat1 Atık Yönetiminin İrdelenmesi ve Yeniden Planlanmas1. Doktora Tezi, Cumhuriyet Üniversitesi, 158.

13. Yilmaz, A., Atmaca, E., 2006. Environmental Geological Assessment of a Solid Waste Disposal Site: a Case Study in Sivas, Turkey. Environmental Geology, 50, 677-689.

14. Kurtman, F., 1973. Sivas-Hafik-Zara ve İmranlı Bölgesinin Jeolojik ve Tektonik Yapısı. MTA Dergi, 80, 1-33.

15. Yilmaz, A., Yilmaz, H., 2006. Characteristic Features and Structural Evolution of a Post Collisional Basin: The Sivas Basin, Central Aatolia, Turkey. Journal of Asian Earth Sciences, 27, 164-176. 